example, sheer recall finds 13 applications, reflective, rationalassociational, and conceptual recall eleven each, and so on down the list to a type which finds only one possible application. This difference is further emphasized by considering that only 4 memory types have 8 or more definite correlations each, while 4 of them have only from 2 to 4 such applications, and the remaining 5 have none at all.

We may now profitably confine our attention to those types of memory which find specific and definite application to algebraic thought. Table III shows that there are 8 of these. Two of this number (reflective, and rational-associational recall) are identical in their application and we shall reduce the number to 7 by considering them as one. Reference to Table I shows that every type of thought process made use of in algebra definitely involves some form of memory to a greater or less degree. From an aggregation of the table we find that in 91 possibilities of application there are 38 actual definite correlations. This would seem to establish beyond question the importance of the memory factor in the study and teaching of algebra.

The matter of the particular application of the different types of recall to the great variety of algebraic situations is a problem for the teacher and the supervisor. We shall endeavor, in the following sections of this discussion, to discover the effect of a consideration of the application of memory to algebraic thought processes in the formulation of a teaching technique and a supervisory program or policy.

(To be concluded.)

\title{
A COMPOSITE COURSE FOR SEVENTH AND EIGHTH GRADE MATHEMATICS.
}

By M. J. Neweil, High School, Evanston, Ill.

A report by the Articulation Committee for Mathematics of the Lake Shore Division of the Illinois Teachers' Association.

Foreword. The territory of the Lake Shore Division of the Illinois Teachers' Association comprises some half dozen counties in the northeast corner of the state exclusive of the city of Chicago. A considerable portion of its population is suburban to the larger city and practically all of its business activities center there. Its educational experiences and problems are not peculiarly its own for all of its communities are vitally Ameri- 
can. It does admit a large foreign element in its population but this is well distributed and eagerly striving to become American. But its compact territory, good transportation, and alert school authorities have all served to keep it well forward in striving for the solution of educational problems.

Organization of Township High Schools. With one or two exceptions ${ }^{7}$ all the secondary schools within a radius of seventyfive miles of the city of Chicago are organized under the Township High School Act. This plan of organization is very popular in Illinois with nearly four hundred such districts already in existence and the number increasing everywhere through the state with the coming of paved roads.

Drawbacks of Township High School. But the township high school tends greatly to magnify the differences in organization, and especially, in methods of instruction that exists everywhere in this country between the elementary school and the secondary school.

(1) The elementary school and the township high school are under distinct school boards, with distinct and absolutely independent teaching forces and superintendents. The high school is not responsible to the elementary school nor is the elementary school in any legal way responsible to the high school.

(2) The township, which is the high school district, usually includes several independent elementary school districts, each with its own school board, its own independent superintendent, and its own methods of meeting educational problems. If one elementary district in a given township has a reasonable population and considerable wealth, it cannot help but work out its problems in a better manner than its neighbor district in the same township, with larger population and less wealth. But under the Township High School Act the secondary school must accept the diplomas from every grade school in its territory and at their face value.

Efforts to Meet Drawbacks. To bring about a better co-ordination between the grades and the high school, many township principals have adopted the plan of making some instructor who is well-known and popular throughout the high school district chief liaisson officer-his duty being to visit all the teachers of the higher elementary grades in their classrooms, study their difficulties at first hand, and present the problem of defieiency in preparation for the upper sehool. Of course this can only be done with the full approval and consent of the grade superintendent. 
Some high schools, ruled out of direct contact with the grade teachers, have aroused their interest and zeal by following the college plan and sending back to each the record of the work in the upper school made by each graduate of the lower during his first semester.

One township high school of the Lake Shore Association has an Articulation Committee appointed from its faculty, one representative for each freshman subject, that meets all the seventh and eighth grade teachers at the high school building several times during the school year. These meetings have served to bring about a fine spirit of cooperation between the teachers of the six elementary sehool districts that comprise the township and the high school. Minimum requirements have been agreed upon for the important grade subjects, notably English and mathematics. Some of the common errors made in the upper school have been listed and some study made of their causes. This particular school has this year, for the first time, attempted to classify all first year students on the basis of the Otis Tests given last spring in the grades, together with the records of the grade teachers and their estimates of ability. It has placed all slower pupils in distinct sections so as to enable them to proceed at their own speed. The reports from such grading should prove interesting.

Such a committee should get on with the problems of students' errors and what should be the carry-over from grades to high school.

Elementary Schools Awake. The elementary school authorities are fully abreast of the problem of better preparation. Each year an increasingly larger per cent of their graduates enter the upper school. Of forty-five who received diplomas from one grade school in June, 1921, forty-three enrolled at the local high school in September. A similar record will be found in many other communities. Professional pride requires that the standard of preparation shall be as high as possible.

Growth of Departmentalized Grade Schools. In northeastern Illinois there has been a steady growth in the number of departmentalized seventh and eighth grade schools ${ }^{6}$. The Township High School Act, which restricts the district thus organized to the control of ninth, tenth, eleventh, and twelfth grades only, is apparently compelling the adoption of the 6-2-4 plan. Such two-year schools are to all intents Junior High School of two grades. Several new buildings and remodeled old buildings bava been entirely given over to the use of such schools. In a 
large number of elementary districts the seventh and eight grade pupils have been assembled from several contiguous wards in suitable rooms of a single convenient building. In smaller elementary districts, that have but a single building, the problem of departmentalizing these grades has been easier. In every district able to pay the bill two or three years will see the reorganization completely worked out. But of course the problem of teacher-preparation and of subject material will require a longer time. Whatever may be the actual advance in quality of preparation for high school due to this movement, at the present it is stirring the enthusiasm and arousing the professional spirit of the teachers.

They are striving to become specialists and are getting away to the summer schools of the universities in increasing numbers. An Articulation Committee. At the annual meeting of the Lake Shore Association in April, 1921, the newly elected president, Principal E. V. Tubbs, of New Trier Township High School, named an Articulation Committee for mathematies consisting of ten grade and four high school teachers of the subject. The membership of this committee was selected with reference to a central meeting place and represents seven grade districts and four township high schools. To it was assigned the problem of better co-ordination. It is interesting to note that President Tubbs has recently named a similar committee for English.

At its first meeting in June the Mathematies Committee decided that its first duty was that of making a composite course that could be adopted with minimum changes throughout the Association. In the immediate suburbs of Chicago there is a constant movement of population and a considerable interchange of pupils during the year. The problem of adjustment to a new school is sufficiently difficult for the ordinary student even when the subject material is quite the same in the new and the old. But when the courses differ as widely as at present in some sections, the adjustment is impossible and a year is lost.

The Composite Course. The following is the composite course agreed upon by the committee. Few schools will need to make any very great change in their present material, time, or manner of its presentation. Furthermore, while not extreme or radical in any way, the committee believes that it holds close to the similar report of the National Committee on Mathematical Requirements. 
Mathematical Topics for the Seventh Gradw.

At the completion of the sixth grade the pupil should be able to perform the fundamental operations with integers, common fractions, and decimals with a fair degreo of speed and aecuracy.

I. Review briefly essential topies of previous grades for aceuraey and against future needs.

II. Percentage and its applications.

1. Its three cases.

2. Change per cents to fractions and vice versa.

3. Choose problems:
a. arising from the home and comnounity,
b. introdueing industry and business,
e. teaching thrift and economy.

III. Intuitive geometry and simple mensuration.

(All geometric terms to be earefully defined and correctly used.)

1. Construetion work with compasses and straight edge.
a. Drawing straight lines and circles.
b. Bisecting line-segments and ares.
e. Construeting and measuring angles.
d. Construeting perpendieulars.
e. Constructing parallel lines.
. $f$. Reproducing and originating designs and patterns.

2. Constructing and using squares, rectangles, parallelograms, triangles, ete., measure lengths, compute areas, and derive the simpler formulas. (The formula as a shorthand.)

IV. Simple interest and its problems.

1. Introduce and use formula, $i=p r t$.

2. Use business terms and methods.

3. Solve investment problems from real estate, postal savings, ete.

V. Graphs-their interpretation and construction.

1. Bar graphs.

2. Cirele graphs.

3. Motivate 1 and 2 with simple problems requiring the expression in per cents or fractions of relative areas of given graphs.

\section{Mathematical Topics for the Eighth Grade.}

I. Review fundamental operations with integers, common fractions, and decimals for speed and aceuracy.

II. Complete the study of pereentage and interest.

1. Successive discounts and other business terms.

2. Banking and its papers.
a. Savings bank interest.

b. Bank discount.

3. Use problems:
a. of investing money, loans, mortgages, stocks and bonds, ete.,
b. teaching the terms and meaning of insurance,
c. teaching the meaning and necessity of taxes,
d. from internal revenue, tariffs, ete.

III. The Pythagorean Theorem and square root.

1. Explain the theorem by squares from cross section paper.

2. Teach method of square root and require reasonable accuracy.

3. Apply the theorem as widely as possible, diagonals, altitudes, ete.

Note.-Topies IV, V, and VI are to be taught in a unified manner.

IV. Mensuration.

i. Review work of seventh grade and construct regular polygons of

6,8 , and 12 sides.

2. Review and complete essential tables of denominate numbers.

3. Board measure and its formula.

4. Surface and volume.

Derive formulas for and apply to problems arising from, (a) trapezoid, (b) circle, (c) equilateral triangle, (d) prism, ( $\theta$ ) eylinder, (f) cone, (g) pyramid, (h) sphere.

V. Simple equations. 
1. Finding value of unknown.

2. Four operations performed on an equation.

3. Solving problems by'equations.

VI. Formulas.

1. Evaluation of.

2. Changing subject.

3. Application to problems.

Note.-Topies VII, VIII, and IX are to be taught in a unified manner.

VII. Ratio and proportion.

1. Meaning of ratio.

2. Meaning of proportion.

3. Applieation to problems.

VIII. Similar figures.

1. Discovery of relationships.

2. Development of idea by problems.

3. Use in drawing maps and plans.

4. Measurement of inaceessible distances.

IX. Graphing.

1. Review of seventh grade work.

2. Problems requiring representation of ratios and per cents by graphs.

3. Construction and interpretation of broken line graphs.

4. Showing functional relation by graphs.

At its future meetings the committee proposes to fill in the outline by naming minor details necessary for perfect development. For instance, it proposes to name what formulas shall be presented and in what order, what types of problems can be used from life and industry and when, what graphs had best be required and along what lines can exploration be made most easily by the pupil.

It proposes to get at the problem of consistent use of terms, for it finds the complaint that the pupil is unable to distinguish between "gain" and "rate of gain," between "sum," "amount," and "principal," etc. It finds that most texts are not consistent in the use of certain expressions. One problem may read: "A sum of money will amount to _._" and a little farther on the pupil will find this: "Two men form a company and their capital amounts to -_." While the number of such inconsistencies in arithmetic cannot be large, yet why should there be a single case?

Articulation Committee for Mathematics, Lake Shore Division Illinois Teachers' Association.

Elma Englebreeht, Elgin Winifred N. Tobin, Elgin Herma Wyman, Wilmette Mary M. Reese, Winnetka Florence Connor, Oak Park Elsie L. Davis, Maywood Alice Jamison, Oak Park
Edwin Schreiber, Maywood

Geo. A. Harper, Kenilworth

Sara Grant, Maywood

Beryl Van Antwerp, Evanston

Stella Stevenson, Evanston

C. M. Austin, Oak Park, Chairman

M. J. Newell, Evanston, Secretary 